\title{
AOR
}

Selected Papers of \#AolR2019:

The $20^{\text {th }}$ Annual Conference of the Association of Internet Researchers Brisbane, Australia / 2-5 October 2019

\section{HOW DOES CRYSTAL KNOW? FOLK THEORIES AND TRUST IN PREDICTIVE ALGORITHMS THAT ASSESS INDIVIDUAL PERSONALITY AND COMMUNICATION PREFERENCES}

Tony Liao

University of Cincinnati

\section{Introduction}

Recent research on algorithms has focused on predictive and hyper-personal algorithms which aim to assess an individual's psychometric attributes, such as personality, attitudes, and preferences (Gou, Zhou, \& Yang, 2014; Warshaw et al., 2015). While the accuracy of these predictive algorithms is still unknown, users are increasingly becoming aware of these algorithms and their use in behavioral advertising (Rader \& Gray, 2015; Ur et al., 2012).

Given this increased awareness, there has been some emerging research into people's responses to algorithms, specifically what kinds of folk theories and assumptions they have for how they work (Devito, Gergle, \& Birnholtz, 2017; Eslami et al., 2016; Gillespie, 2014; Rader \& Gray, 2015). While some of these studies have examined how people react to a personality algorithms making predictions based on social media posts (Gou, Zhou, \& Yang, 2014; Warshaw et al., 2015), these were recommendation programs created by researchers. This study builds on that work by examining a real world deployment of these technologies and how people respond to those profiles. This study focuses on Crystal Knows, a company that algorithmically generates personality profiles, often unbeknownst to an individual.

\section{CrystalKnows}

Founded in 2015, CrystalKnows claims to have the world's largest personality platform. Without explicitly asking users, CrystalKnows automatically generates a personality profile for certain users through an algorithm that captures and sorts public data online. The profile includes a set of personality indicators as well as recommendations for how Suggested Citation (APA): Liao, T. (2019, October 2-5). How Does Crystal Know? Folk Theories And Trust In Predictive Algorithms That Assess Individual Personality And Communication Preferences. Paper presented at AolR 2019: The $20^{\text {th }}$ Annual Conference of the Association of Internet Researchers. Brisbane, Australia: AolR. Retrieved from http://spir.aoir.org. 
to communicate and interact with this person (e.g., don't use lengthy formal language, etc.).

While recent work has broadened our understanding of people's folk theories about algorithms (Eslami et al., 2016; Rader \& Gray, 2015; Warshaw et al., 2015), this study builds on this line of research in important ways. First, much of the existing work has focused on people's perceptions of algorithms in systems where people are actively contributing information. CrystalKnows is an algorithmically generated profile generated across platforms which users may not have knowingly or intentionally entered information. Second, while initial studies have found that people tend to trust algorithmic personality recommendations, they have also found that most perceive them as creepy, and worry about who has access to them (Warshaw et al., 2015). Unlike other algorithmic services that make declarative statements about personality, CrystalKnows goes further by actively making predictions and recommendations for how best to communicate with an individual. They also offer in-depth reports about how people might work together, and how a person (and groups of people) would perform under certain work environments.

Given the emerging creation of these profiles, this study asks the following research questions:

RQ1) How do people perceive the accuracy of algorithmically generated profiles that were created without their prior knowledge?

RQ2) How do people rationalize their past online practices and sources of information that contribute to and enable the algorithmically generated profile?

RQ3) How do people perceive the appropriateness of communication recommendations that the algorithm makes about them?

\section{Methods}

Participants were recruited at a university in the Midwest United States. We first asked for their permission to search their names in the CrystalKnows database. If they gave consent, we checked to see if their profiles existed on the site. Only participants who already had a pre-existing profile were invited to participate. They were given their CrystalKnows profile (Figure 1) to review before participating in a semi-structured interview. Interviews ( $\mathrm{N}=31$ ) were audio-recorded, transcribed and entered in the qualitative data analysis program Dedoose. 
What Comes Naturally to Dan

$$
\begin{aligned}
& \text { LOYALTY INVENTIVENESS PROBLEM SOLVING } \\
& \text { CONTINGENCy planning Meticulous research }
\end{aligned}
$$

Dan is confident, insightful, and enjoys deep discussion to understand a particular issue. He may become introverted in high-pressure environments, especially when faced with conflict and dissenting opinions. Dan builds trust slowly and values

loyalty within his close circle.

\section{When Speaking to Dan}

$$
\begin{aligned}
& \text { ASK QUESTIONS DON'T EXAGGERATE } \\
& \text { SPEAK MATTER-OF-FACTLY AVOID INTERRUPTIONS }
\end{aligned}
$$$$
\text { REMAIN OBJECTIVE }
$$

Dan appreciates when you ask questions, it helps keep his attention and taps into his curiosity. He has a tendency to go off on a tangent when excited by a topic of interest. He will appreciate gentle interruption to re-align the conversation, just make sure to provide reasoning for your statements.

\section{What Motivates Dan}

$$
\text { peerapproval clearexpectations gaining knowledge }
$$$$
\text { DEVELOPING NEW SKILLS FEELING PREPARED }
$$

\section{To convince Mackenzie}

Share a customer story instead of listing features

Talk about topics unrelated to work

Explain how this will help their entire team

Encourage them to talk it over with peers

Relationship: Mackenzie tends to place a lot of trust in personal rapport when making a decision. It may be helpful if Tony highlights mutual contacts between them.

\section{(Figure 1)}
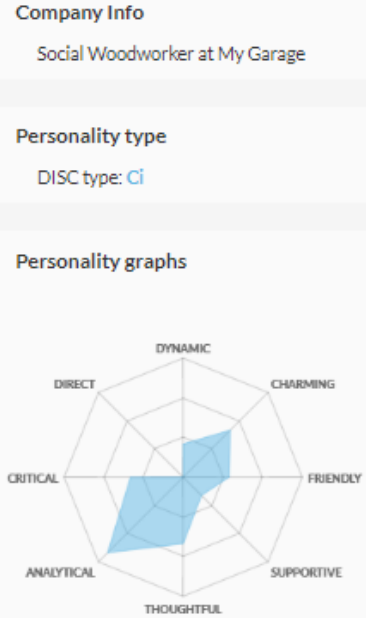

Switch to DISC graph

Profile accuracy

$80 \%$

How would you rate this report?

V Very Accurate

Mostly Accurate

\section{Findings}

\section{Folk Theories about Information Sources}


Because CrystalKnows does not reveal how they obtain their data, participants constructed their own theories for where their profile information came from, based on the specific recommendations offered and their own speculation. Here there was a combination of fear of algorithms as all-knowing and some personal reflection about their social media presence that these algorithms are drawing from.

\section{Rationalization about Recommendations}

Many of the most interesting responses occurred when people were asked why they thought the algorithm produced a particular recommendation (e.g. include as much information as possible when messaging $x$ person). Based on limited evidence, they would construct complex scenarios and volunteer personal practices or instances where they may have developed certain communicative habits to explain the accuracy of the algorithm, building on a theory of these algorithms as all encompassing.

\section{Fear/Concern about Creation and Use of Algorithmic Profile}

When asked about how they felt about the existence of this profile and certain entities using their information, many expressed concern. While with advertising, people could revel in the small mistakes that the algorithm made, these could become significant points of worry and potentially discrimination if used to determine hiring practices and team construction (e.g. X may become introverted in high-pressure environments).

\section{Conclusion}

While early work in folk theories of algorithms like the Personal Engagement theory (feed curation based on total interactions), Global Popularity theory (total number of likes/comments), and others are specific to social media newsfeeds (Eslami et a., 2016), CrystalKnows poses a different set of questions about individual psychometric algorithms, and these different responses build on our existing understanding of perceptions of algorithms.

Given their increasing use, there needs to be more work examining these algorithmic personality profiles and how people respond to algorithmic predictions about themselves without their consent (Warshaw et al., 2015). CrystalKnows is selling their profiles as a tool for advertising firms as well as companies making hiring decisions or forming teams. It is important to know what the algorithm produces, how people think they are generated, and whether they trust the system that makes these predictions. 


\section{References}

DeVito, M. A., Gergle, D., \& Birnholtz, J. (2017, May). Algorithms ruin everything:\# RIPTwitter, Folk Theories, and Resistance to Algorithmic Change in Social Media. In Proceedings of the 2017 CHI Conference on Human Factors in Computing Systems (pp. 3163-3174). ACM.

Eslami, M., Karahalios, K., Sandvig, C., Vaccaro, K., Rickman, A., Hamilton, K., \& Kirlik, A. (2016, May). First I like it, then I hide it: Folk theories of social feeds. In Proceedings of the 2016 CHI conference on human factors in computing systems (pp. 2371-2382). ACM.

Gillespie, T. (2014). The relevance of algorithms. Media technologies: Essays on communication, materiality, and society, 167.

Gou, L., Zhou, M. X., \& Yang, H. (2014, April). KnowMe and ShareMe: understanding automatically discovered personality traits from social media and user sharing preferences. In Proceedings of the SIGCHI Conference on Human Factors in Computing Systems (pp. 955-964). ACM.

Rader, E., \& Gray, R. (2015, April). Understanding user beliefs about algorithmic curation in the Facebook news feed. In Proceedings of the 33rd annual ACM conference on human factors in computing systems (pp. 173-182). ACM.

Ur, B., Leon, P. G., Cranor, L. F., Shay, R., \& Wang, Y. (2012, July). Smart, useful, scary, creepy: perceptions of online behavioral advertising. In proceedings of the eighth symposium on usable privacy and security (p. 4). ACM.

Warshaw, J., Matthews, T., Whittaker, S., Kau, C., Bengualid, M., \& Smith, B. A. (2015, April). Can an Algorithm Know the Real You?: Understanding People's Reactions to Hyperpersonal Analytics Systems. In Proceedings of the 33rd Annual ACM Conference on Human Factors in Computing Systems (pp. 797-806). ACM. 